\title{
Critérios de sucesso em projetos: um estudo exploratório considerando a interferência das variáveis tipologia de projetos e stakeholders
}

\author{
Julia Garaldi Borges ${ }^{\mathrm{a}}$, Marly Monteiro de Carvalho ${ }^{\mathrm{b} *}$ \\ aborges.julia@gmail.com, POL1/USP, Brasil \\ b*marlymc@usp.br, POL1/USP, Brasil
}

\begin{abstract}
Resumo
O objetivo deste trabalho é compreender a influência das variáveis tipologia de projeto e tipo de stakeholder nos critérios de sucesso em projetos. A abordagem metodológica envolveu em uma primeira fase uma revisão da literatura, seguida de uma pesquisa de campo com estratégia híbrida, qualitativa e quantitativa. A pesquisa foi desenvolvida em uma empresa de engenharia e soluções integradas de infraestrutura com atuação em diversos setores. 0 trabalho de campo envolveu coleta e análise de dados de 54 projetos e um levantamento com 59 gerentes e outros envolvidos na atividade de projeto para identificar a importância dos critérios de sucesso. Os resultados apontam para uma influência significativa do tipo de projeto na importância dos critérios de sucesso, no entanto o mesmo não ocorreu para o tipo de stakeholder.
\end{abstract}

Palavras-chave

Gestão de projetos. Avaliação de desempenho em projetos. Tipologia. Stakeholder. Teoria contingencial.

\section{Introdução}

Nos últimos anos, a execução de projetos tem recebido elevado foco, em função das necessidades de as organizações desenvolverem iniciativas que busquem inovação e vantagem competitiva (Shenhar \& Dvir, 2007). Dessa forma, projetos passaram a representar uma parcela significativa dos investimentos das empresas, sendo o seu adequado acompanhamento fundamental para a avaliação do desempenho das organizações e, consequentemente, para o processo de tomada de decisão.

Seguindo essa tendência, a gestão de projetos tem sido cada vez mais relacionada à gestão do negócio e não apenas a uma atividade operacional isolada. Nessa evolução do gerenciamento de projetos, a definição de sucesso também se desenvolveu, partindo da simples combinação entre custo, prazo e qualidade para múltiplos critérios, que envolvem não somente o projeto mas também o negócio da organização (Kerzner, 2010). Dessa forma, verifica-se a necessidade da adequação dos fatores de sucesso dos projetos das organizações, de forma que eles estejam alinhados com o negócio da empresa e os seus objetivos estratégicos.

Discute-se também a aplicabilidade de uma metodologia universal de gerenciamento de projetos a todos os tipos de projetos, ou seja, a existência de um conjunto de critérios capazes de determinar o sucesso de todo e qualquer tipo de projeto (one-sizefits-all) (Balachandra \& Friar, 1997). Este trabalho alinha-se à perspectiva contingencial, que tem evoluído na pesquisa acadêmica, em que se sugere uma abordagem mais customizada às características do projeto, e na qual um método não se ajusta a todas as contingências do projeto (one-size-does-not-fit-all), tais como tipo do projeto e tipo de stakeholders. Nesta pesquisa, além de a tipologia de projetos influenciar na definição das dimensões de sucesso de um projeto, os stakeholders a ele relacionados também exercem influência sobre esta questão, uma vez que possuem necessidades de informações distintas, de acordo com 
suas expectativas sobre determinado empreendimento. Dessa forma, os critérios de sucesso utilizados para medir o desempenho de projetos devem ser analisados sob uma perspectiva contingencial.

0 objetivo do presente trabalho é compreender a relação entre critérios de sucesso em projetos, considerando-se a influência das variáveis tipologia de projeto e tipo de stakeholder.

Este artigo está estruturado em seis seções. A seção 2 traz a síntese do quadro teórico, seguindo-se a metodologia de pesquisa adotada, na seção 3. A seção 4 traz a análise dos 54 projetos, enquanto a seção 5 apresenta os resultados do levantamento tipo survey. Finaliza o artigo a seção 6 , com as conclusões e recomendações para trabalhos futuros.

\section{Critérios de sucesso em projetos: síntese do quadro teórico}

0 tema sucesso em projetos é um dos mais discutidos na área de gerenciamento de projetos, porém com um nivel de consenso bastante baixo entre os pesquisadores, como sugerem Pinto \& Slevin (1988).

Para De Wit (1988), Pinto \& Slevin (1988), Fortune \& White (2006) e outros autores, a definição de sucesso em projetos é contingencial, como será discutido na próxima seção, pois depende da tipologia e da fase. Além disso, Sanvido et al. (1992) ressaltam a dificuldade de se medir tal sucesso, já que a sua definição também pode variar de acordo com as expectativas dos diversos stakeholders envolvidos.

Elattar (2009) sugere uma série de critérios de sucesso categorizados de acordo com as perspectivas de diferentes stakeholders: o proprietário, o desenvolvedor e o contratado.

Toor \& Ogunlana (2009) também analisaram os pontos de vista de diferentes stakeholders com base em respostas a um questionário de pesquisa aplicado a clientes, consultores de gerenciamento de projeto, consultores de supervisão de construção, consultores de design e construtoras contratadas. Com exceção do cliente, que demonstrou valorização primariamente do uso eficiente dos recursos, o cumprimento do prazo foi definido como o principal critério de sucesso pelas demais categorias de profissionais consultados.

Lim \& Mohamed (1999) consideram que o sucesso do projeto deve ser visto de diferentes perspectivas (cliente, desenvolvedor, contratante, usuário etc.), em uma perspectiva micro (prazo, custo, qualidade, desempenho e segurança) e macro (satisfação, utilidade e operação).

Para se definir sucesso em projetos é importante ter-se clara a distinção entre os seguintes termos: sucesso do gerenciamento de projetos e sucesso do projeto. Segundo De Wit (1988) e PMl (Project Management Institute, 2008), o sucesso do gerenciamento de projetos é medido por meio da avaliação de critérios que envolvem medidas tradicionais como custo, prazo e qualidade. Já com relação ao sucesso do projeto, tanto Barclay (2008) quanto De Wit (1988) mencionam a importância da consideração dos objetivos dos stakeholders, sendo que o último reforça a consideração dos objetivos de todos os stakeholders envolvidos no ciclo de vida do projeto, em todos os níveis da hierarquia gerencial. Pode-se definir ainda sucesso a partir do produto ou resultado final do projeto e a satisfação dos stakeholders (Cooke-Davies, 2002).

Outros termos bastante mencionados na literatura e cuja definição é muitas vezes confundida são critérios de sucesso e fatores de sucesso. Critérios de sucesso são medidas a partir das quais o sucesso ou fracasso de um projeto é julgado. Já fatores de sucesso são as entradas do sistema gerencial que levam direta ou indiretamente ao sucesso do projeto (De Wit, 1988). 0 presente trabalho se concentra nos critérios de sucesso.

Muitos autores, como Navarre \& Schaan (1990), Belassi \& Tukel (1996) e Hatush \& Skitmore (1997), atrelam o sucesso de projetos às medidas de desempenho de custo, prazo e qualidade, posteriormente denominadas "triângulo de ferro" por Atkinson (1999). Apesar de amplamente citados na literatura, esses critérios são considerados por muitos autores como insuficientes para medir-se o sucesso de projetos.

Assim como Pinto \& Slevin (1988) e De Wit (1988) critica a abordagem simplista de medida de sucesso em projetos pela restrição tripla, defendendo que a maneira mais adequada para obter-se tal medida é por meio dos objetivos dos projetos. De Wit (1988) apresenta ainda alguns outros critérios de sucesso, como satisfação do cliente, funcionalidade, satisfação do contratante e satisfação do gerente do projeto e sua equipe, além do desempenho orçamentário e de prazo.

Siegelaub (2010), fazendo menção à metodologia PRINCE2 (Office of Government Commerce, 2005), apresenta a chamada "sêxtupla restrição", composta pelas já previstas custo, prazo, qualidade e escopo, com adição das restrições benefício e risco. A dimensão benefícios representa o valor que se espera que o projeto entregue à organização, expresso com objetivos mensuráveis e alcançáveis. 0 autor destaca a interrelação entre essas dimensões, uma vez que alterações numa determinada dimensão afetam as demais. 
Pocock et al. (1996), por sua vez, propõem a consideração de critérios judiciais, como a ausência de processos legais.

Atkinson (1999) propõe uma divisão para o entendimento dos diversos critérios para medida do sucesso de projetos, separados nas seguintes categorias: triângulo de ferro, sistemas de informação, benefícios para a organização e benefício para os stakeholders.

Alguns trabalhos na área de construção civil começam a incorporar também aspectos de sustentabilidade nos critérios de sucesso. Chan \& Chan (2004) procuraram resumir e consolidar os diversos critérios de sucesso de projetos de construção apresentados na literatura, destacando, além dos já mencionados qualidade, custo, prazo, satisfação dos participantes, expectativas e satisfação dos usuários, aspectos relacionados à sustentabilidade, como desempenho ambiental, saúde e segurança, valor e lucratividade comercial.

Ainda no setor de construção, a organização Construction Industry Institute (Cll), consórcio formado em 1983, composto por proprietários, empresas de construção, acadêmicos e outros interessados nessa indústria, também sugere um conjunto de critérios de sucesso de projetos. A ferramenta conhecida como Project Health Indicator Tool (PHIT) distingue os critérios de desempenho de projetos em duas categorias (Constructon Industry Institute, 2006): critérios atrelados aos resultados do projeto (custo, cronograma, qualidade, segurança e satisfação) e critérios ligados a práticas de gerenciamento de projetos (alinhamento, gestão da mudança, "construtabilidade", contratação, gestão da qualidade, práticas de segurança, controle do projeto e desenvolvimento da equipe). Kometa et al. (1995) também salientam aspectos de segurança, economia (custo de construção), custo de manutenção, tempo e flexibilidade para os usuários; enquanto Kumaraswamy \& Thorpe (1996) listam os tradicionais orçamento, cronograma, qualidade da mão de obra, satisfação do cliente e do gerente de projeto junto aos critérios transferência de tecnologia, respeito ao ambiente, saúde e segurança.

Shenhar \& Dvir (2007) fazem um esforço de agrupamento das métricas de sucesso em categorias. Para eles, a maioria dos projetos das organizações integra sua gestão estratégica e, por isso, devem ser avaliados com base na sua contribuição ao resultado final da empresa. Dessa forma, os autores sugerem que o sucesso dos projetos seja abordado multidimensionalmente, refletindo a intenção estratégica da empresa e seus objetivos de negócio. Partindo desse pressuposto, os autores sugerem uma avaliação do sucesso do projeto no curto e longo prazos baseando-se em cinco categorias: eficiência; impacto para o cliente; impacto na equipe; negócio e sucesso direto; e preparação para o futuro
Shenhar \& Dvir (2007) reforçam que a estrutura sugerida, apesar de ser aplicável a uma extensa gama de projetos, não é universal. Os projetos devem ser cuidadosamente analisados e deve-se atentar para a necessidade de, quando necessário, incluirem-se novas perspectivas ou seja, uma abordagem contingencial para a definição dos critérios de sucesso relevantes para a organização e seus projetos.

Com base na literatura pesquisada para identificação dos critérios de sucesso foi proposto um quadro síntese em que os critérios de desempenho foram agrupados em categorias (ver Tabela 1). Foram consideradas e adaptadas as categorias propostas por Shenhar \& Dvir (2007), adicionando-se uma nova dimensão de critérios denominada sustentabilidade.

\subsection{Abordagem contingencial}

A questão contingencial tem sido normalmente ignorada pela literatura de gerenciamento de projetos, que assume, muitas vezes, que todos os projetos partilham do mesmo universo de características gerenciais, o que sugere a ideia de padronização do gerenciamento de projetos através dos guias de referência (Shenhar, 2001; Carvalho \& Rabechini Junior, 2011).

No entanto, alguns autores têm questionado esse ponto de vista, reforçando uma abordagem contingencial que enfoca a necessidade de gestão de projetos de acordo com suas características e não de forma universal

Segundo Shenhar et al. (2005), o mito de que "um método se ajusta a todos" (one-size-fits-all) (Balachandra \& Friar, 1997) conduziu, frequentemente, para o fracasso e descontentamento com a área de gestão de projetos. Em suas pesquisas (Shenhar, 2001; Shenhar et al., 2002, 2005), os autores argumentam que de fato o conceito de que "um método não se ajusta a todos" (one-size-does-not-fit-all) é não só teoricamente mais fundamentado em pesquisa acadêmica como também mais aplicável no mundo real. Os autores identificaram evidências empíricas de que os fatores de sucesso de projetos são fortemente dependentes da natureza deles e, portanto, para cada tipo de projeto os fatores significativos são distintos.

De fato inúmeras variáveis podem afetar o gerenciamento de projetos e os fatores críticos para o seu sucesso, tais como a tipologia do projeto e o tipo de stakeholder, como será aprofundado a seguir.

\subsubsection{Tipologia de projetos}

0 grau de complexidade de projetos é uma dimensão comumente abordada no contexto de tipologias. Clark \& Fujimoto (1991) propuseram 
Tabela 1. Critérios de sucesso categorizados

\begin{tabular}{|c|c|c|}
\hline Categorias & Critérios de sucesso & Referência bibliográfica \\
\hline \multirow{5}{*}{ 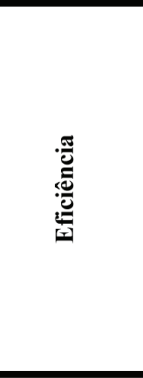 } & Cumprimento de cronograma (prazo) & $\begin{array}{l}\text { Shenhar e Dvir (2007), Navarre e Schaan (1990), Belassi e Tukel } \\
\text { (1996), Hatush e Skitmore (1997), De Wit (1988), OGC (2005), } \\
\text { Atkinson (1999), CII (2006), Kumaraswamy e Thorpe (1996), Lim e } \\
\text { Mohamed (1999) }\end{array}$ \\
\hline & Cumprimento do orçamento (custo) & $\begin{array}{l}\text { Shenhar e Dvir (2007), Navarre e Schaan (1990), Belassi e Tukel } \\
\text { (1996), Hatush e Skitmore (1997), De Wit (1988), OGC (2005), } \\
\text { Atkinson (1999), CII (2006), Kumaraswamy e Thorpe (1996), Lim e } \\
\text { Mohamed (1999) }\end{array}$ \\
\hline & Capacidade dos fornecedores & Atkinson (1999) \\
\hline & Clareza na comunicação & $\begin{array}{l}\text { Elattar (2009), Fortune e White (2006), Kerzner (1987), Pinto e } \\
\text { Slevin (1987) }\end{array}$ \\
\hline & Presença de desvios & Shenhar e Dvir (2007), CII (2006) \\
\hline \multirow{5}{*}{ 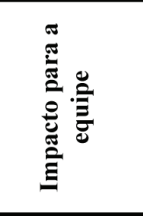 } & Alta satisfação ou moral da equipe & Shenhar e Dvir (2007), De Wit (1988), Elattar (2009), CII (2006) \\
\hline & $\begin{array}{l}\text { Desenvolvimento das capacidades e } \\
\text { habilidades da equipe }\end{array}$ & Shenhar e Dvir (2007), CII (2006), Atkinson (1999) \\
\hline & Retenção dos membros da equipe & Shenhar e Dvir (2007) \\
\hline & Ausência de conflitos & Shenhar e Dvir (2007) \\
\hline & Satisfação do gerente do projeto & De Wit (1988), Kumaraswamy e Thorpe (1996) \\
\hline \multirow{7}{*}{ 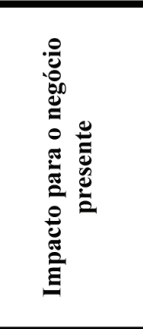 } & $\begin{array}{l}\text { Medidas econômicas: vendas, lucro, } \\
\text { ROI, ROE }\end{array}$ & Shenhar e Dvir (2007), De Wit (1988), Elattar (2009) \\
\hline & Parcela de mercado & Shenhar e Dvir (2007) \\
\hline & Fluxo de caixa & Shenhar e Dvir (2007) \\
\hline & Qualidade do serviço & $\begin{array}{l}\text { Shenhar e Dvir (2007), De Wit (1988), OGC (2005), Atkinson } \\
\text { (1999), Toor e Ogunlana (2009), CII (2006) }\end{array}$ \\
\hline & Nível de risco & De Wit (1988), OGC (2005) \\
\hline & Aprendizado profissional & Atkinson (1999) \\
\hline & Atendimento às metas estratégicas & Atkinson (1999) \\
\hline \multirow{4}{*}{ 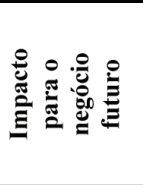 } & Tecnologia nova & Shenhar e Dvir (2007), Kumaraswamy e Thorpe (1996) \\
\hline & Mercado novo & Shenhar e Dvir (2007) \\
\hline & Nova competência essencial & Shenhar e Dvir (2007) \\
\hline & Nova capacidade organizacional & Shenhar e Dvir (2007) \\
\hline \multirow{4}{*}{ 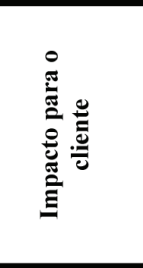 } & $\begin{array}{l}\text { Cumprimento de requisitos e } \\
\text { especificações (escopo) }\end{array}$ & $\begin{array}{l}\text { Shenhar e Dvir (2007), Navarre e Schaan (1990), Belassi e Tukel } \\
\text { (1996), Hatush e Skitmore (1997), De Wit (1988), OGC (2005), } \\
\text { Elattar (2009), Toor e Ogunlana (2009), CII (2006) }\end{array}$ \\
\hline & $\begin{array}{l}\text { Benefícios para o cliente (melhoria de } \\
\text { desempenho) }\end{array}$ & Shenhar e Dvir (2007), OGC (2005) \\
\hline & Satisfação e lealdade do cliente & $\begin{array}{l}\text { Shenhar e Dvir (2007), De Wit (1988), Kumaraswamy e Thorpe } \\
\text { (1996), Lim e Mohamed (1999) }\end{array}$ \\
\hline & Reconhecimento da marca & Shenhar e Dvir (2007) \\
\hline \multirow{4}{*}{ 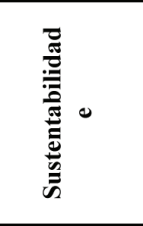 } & Respeito ao meio ambiente & Atkinson (1999), Elattar (2009), Kumaraswamy e Thorpe (1996) \\
\hline & Respeito à sociedade & Atkinson (1999), Elattar (2009), Kumaraswamy e Thorpe (1996) \\
\hline & Conformidade com normas e legislação & Shenhar e Dvir (2007), Pocock et al. (1996), Elattar (2009) \\
\hline & Segurança & $\begin{array}{l}\text { Elattar (2009), Toor e Ogunlana (2009), CII (2006), Kometa, } \\
\text { Olomolaiye e Harris (1995), Lim e Mohamed (1999), Kumaraswamy } \\
\text { e Thorpe (1996) }\end{array}$ \\
\hline
\end{tabular}

uma classificação de acordo com a complexidade de composição interna do produto e da sua interface com o cliente. Vidal \& Marle (2008) propuseram quatro famílias de fatores para caracterizar a complexidade dos projetos: o tamanho do sistema do projeto, a sua variedade, suas interdependências e a dependência do projeto quanto ao seu contexto.

Outros autores propuseram tipologias multidimensionais. Cleland \& King (1967) e Maximiano (1997) propõem tipologias bidimensionais, nas quais a dimensão da complexidade é relacionada à dimensão incerteza

Shenhar et al. (2005) e Shenhar \& Dvir (2007) propõem quatro dimensões, que compõem um diamante (Practical NCTP “Diamond” Model): novidade (novelty), complexidade (complexity), tecnologia (technology) e passo (pace).

Por outro lado, Evaristo \& Van Fenema (1999) apresentam uma forma de classificação de projetos de acordo com a sua composição (projeto único 
ou múltiplos projetos) e a quantidade de pontos de localização (localização única ou localizações múltiplas).

Levando em consideração a relação dos projetos com as estratégias da organização, o escritório de comércio do Reino Unido (Office of Government Commerce - OGC), no seu guia de conhecimento denominado Managing Successful Programmes (MSP), apresenta três categorias de classificação de programas, aplicáveis também a projetos, quais sejam:

-Vision-led (visionário): Entrega uma visão claramente definida, tem uma abordagem de cima para baixo e foca na oportunidade estratégica ou inovadora, como uma transformação radical do negócio, cultura ou ambos;

-Emergent (emergente): Surge de atuais iniciativas não coordenadas e exige uma abordagem conjunta, com uma visão emergente e um objetivo final;

- Compliance (obrigatório): Também chamado de programa must do (tem que fazer); a organização não tem outra escolha que não mudar devido às forças do mercado ou devido ao potencial negativo de não mudar (Office of Government Commerce, 2002).

Westerveld (2003), classificando projetos quanto a sua orientação, em seu Modelo de Excelência de Projeto (Project Excellence Model), propõe uma tipologia baseada em cinco categorias de projetos: orientado ao produto; orientado à ferramenta; orientado ao sistema; orientado à estratégia; e gestão de projeto total.

A abordagem contingencial apoia-se na construção de tipologias que permitem criar roteiros gerenciais em tipos mais homogêneos de projetos, segundo dimensões relevantes para o contexto analisado (Rabechini Junior \& Carvalho, 2009). Baseando-se no conceito de avaliação por grupos de variáveis, propuseram uma tipologia de projetos abalizada em quatro eixos considerados essenciais para a gestão de projetos, no formato de quatro ls: integração, inovação, impacto e imediato.

Existem, portanto tipologias disponíveis, mas os autores salientam que as organizações devem buscar dimensões relevantes em seu contexto singular, criando tipologias próprias para classificar seus projetos (Shenhar et al., 2005; Shenhar \& Dvir, 2007; Rabechini Junior \& Carvalho, 2009).

\subsubsection{Tipo de stakeholder}

A chamada literatura clássica de stakeholders é marcada pela obra de Robert Edward Freeman, Strategic Management: A Stakeholder Approach. Inicialmente mencionado em um memorando internacional no Instituto de Pesquisa de Stanford, em 1963, a definição do termo stakeholders estava relacionada à ideia de sobrevivência, já que eram considerados grupos que suportavam a organização, sem os quais ela não poderia existir. Freeman (1984) relacionou o conceito stakeholder a indivíduo ou grupo de pessoas que podem afetar ou ser afetados pelos objetivos da organização. 0 autor também propõe uma divisão de análise dos stakeholders em três níveis: racional, de processos e transacional. 0 nível racional busca o entendimento de quem são os stakeholders da organização e quais são seus interesses, fazendo uso de mapas e grids para melhor analisar os grupos identificados. 0 nível de processo analisa como a organização gerencia suas relações com seus stakeholders (implícita ou explicitamente). Por fim, o nível transacional busca o entendimento das diversas transações e negociações entre a organização e seus stakeholders.

Mitchell et al. (1997) propõem que se podem identificar classes de stakeholders a partir da existência de um ou mais dos seguintes atributos de relacionamento: poder, legitimidade e urgência. 0 poder representa a capacidade de imposição de vontade. A legitimidade relaciona-se com a percepção ou suposição de que determinadas ações são desejáveis e apropriadas dentro de um determinado contexto social composto por normas, valores, crenças e definições. Urgência é o grau de atenção requerida pelas necessidades dos stakeholders. A existência desses atributos e sua intensidade definem o nivel de saliência, ou destaque, que os stakeholders adquirem sob a perspectiva da alta gerência.

Cummings \& Doh (2000) propuseram a identificação de stakeholders baseada na sua maneira de interagir em três contextos criadores de valor para a organização: o contexto de mercado, o contexto político-social e o contexto tecnológico.

No contexto específico de projetos, Kerzner (2010) define a gestão do relacionamento com stakeholders como o processo de gerenciar suas expectativas, sem comprometer a visão e missão da organização. Nesse processo, o autor propõe atividades como identificação, classificação e mapeamento dos stakeholders. 0 PMI (Project Management Institute, 2008) sugere o mapeamento dos stakeholders de acordo seu nível de poder e interesse.

\section{Metodologia}

Conforme mencionado na seção introdutória, o trabalho busca avaliar o sucesso de projetos, considerando a influência do tipo de projeto e do tipo de stakeholder. 
Em uma etapa preliminar, foi feito um levantamento bibliográfico sistemático nas principais bases científicas de dados pelo portal de periódicos da Capes sobre os três temas principais da pesquisa, critérios de avaliação de sucesso em projetos, tipologias de projetos e de stakeholders, apresentada na seção anterior.

A pesquisa utilizou vários tipos de evidências coletadas junto às bases de dados da empresa estudada, bem como entrevistas com a equipe do Escritório de Gestão de Projetos (PMO - Project Management Office) e um levantamento junto aos gerentes de projeto (ver Figura 1).

Para o levantamento das informações sobre os diversos projetos desenvolvidos pela organização, a partir de indicações dadas pelo responsável pelo PMO, foram consultadas planilhas de controle de projetos e o sistema integrados de gestão (ERP - Enterprise Resource Planning) da empresa. Por não haver uma base de dados única e consolidada, um extenso levantamento de dados foi feito, sendo posteriormente validado pelo responsável pelo PMO. Os dados obtidos nessa fase serviram de base para a definição das tipologias de projeto, bem como para o levantamento dos stakeholders envolvidos.

0 levantamento tipo survey realizado junto aos gerentes de projetos foi feito por meio da internet. Foi elaborado um questionário on-line, interativo e de fácil preenchimento, na ferramenta de pesquisa de livre acesso denominada Google Docs. 0 questionário foi composto por três grupos de questões: caracterização do projeto e do respondente (questões 1 e 2), análise dos critérios de sucesso de projetos (questões de 3 a 8) e abertura para comentários e sugestões (questão 9). 0 detalhamento de cada questão quanto à variável analisada, o tipo de opção de resposta e as possíveis alternativas estão apresentados no Tabela 2.

Cada profissional da amostra recebeu um e-mail personalizado com instruções para o preenchimento do formulário eletrônico, o projeto que deveria avaliar e uma breve explicação sobre o conteúdo que seria abordado no estudo. A pesquisa foi previamente validada pela diretoria da empresa e os respondentes foram previamente informados pela própria direção do PMO sobre a pesquisa que seria realizada, o seu conteúdo e a importância da contribuição dos respondentes. Foram obtidas 59 respostas das 68 esperadas, índice de resposta de $87 \%$. Os profissionais que não responderam a pesquisa detinham cargo de diretor ou gerente de projeto. Dentre os motivos para a não resposta ao questionário incluem-se: férias ou indisponibilidade de tempo.

Os resultados do levantamento foram analisados a partir de duas técnicas estatísticas: o teste de mediana de Mood (Mood Median Test) e a análise fatorial.

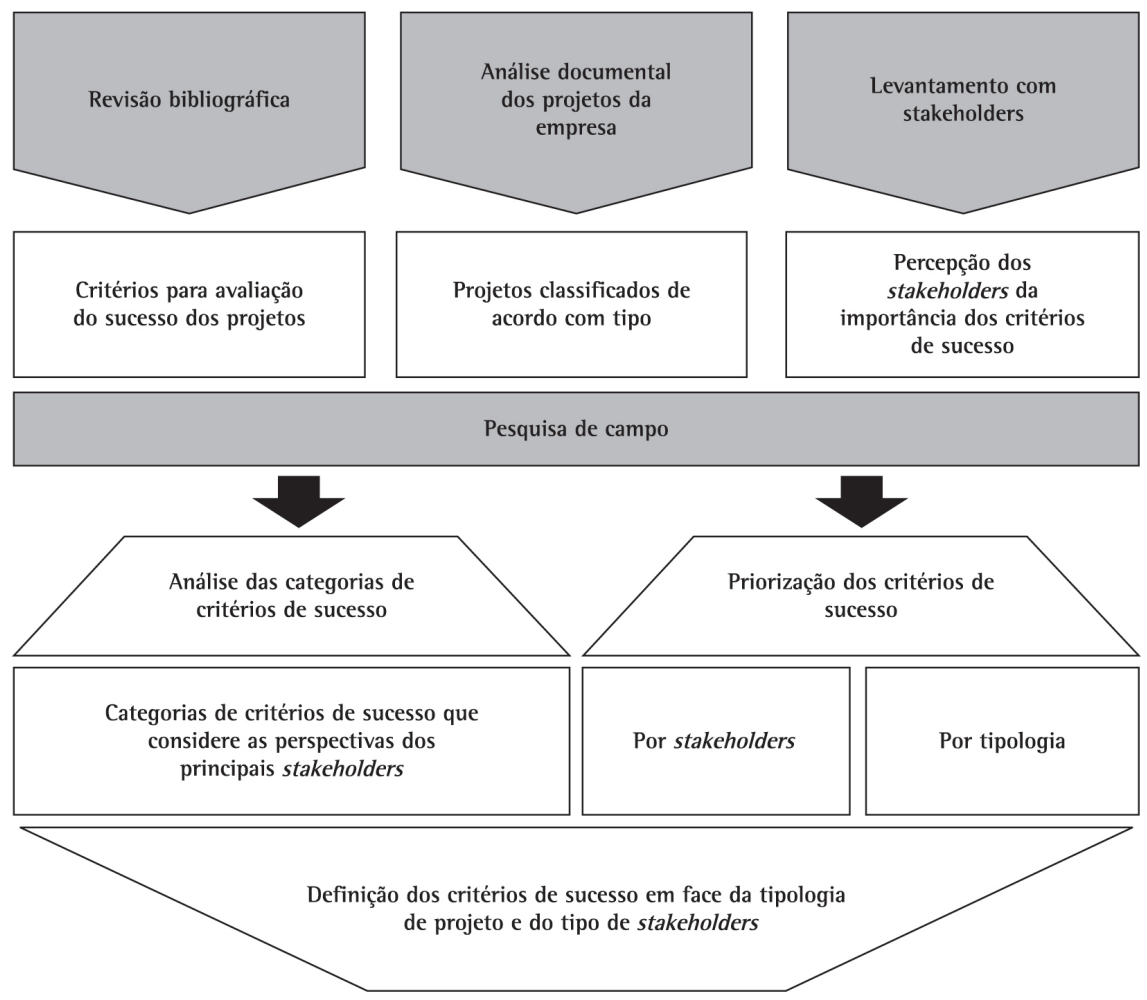

Figura 1. Estrutura da pesquisa de campo. 
Tabela 2. Detalhamento das questões do questionário aplicado.

\begin{tabular}{|c|c|c|c|}
\hline Questão & Variável analisada & Tipo & Alternativas \\
\hline 1 & Projeto & $\begin{array}{l}\text { Caixa de } \\
\text { combinação }\end{array}$ & $\begin{array}{l}\text { Lista dos projetos } \\
\text { sendo analisados }\end{array}$ \\
\hline 2 & Stakeholder & $\begin{array}{l}\text { Caixa de } \\
\text { combinação }\end{array}$ & $\begin{array}{lr}\text { Lista das } & \text { possíveis } \\
\text { funções } & \text { dos } \\
\text { stakeholders } & \\
\text { analisados } & \end{array}$ \\
\hline 3 & Critérios de sucesso de eficácia & $\begin{array}{l}\text { Botão de } \\
\text { opção }\end{array}$ & \multirow{6}{*}{$\begin{array}{l}\text { Escala linkert: } \\
\text { (0) Não aplicável } \\
\text { (1) Irrelevante } \\
\text { (2) Pouco relevante } \\
\text { (3) Importante } \\
\text { (4) Muito importante }\end{array}$} \\
\hline 4 & $\begin{array}{c}\text { Critérios de sucesso de impacto para a } \\
\text { equipe }\end{array}$ & $\begin{array}{c}\text { Botão de } \\
\text { opção }\end{array}$ & \\
\hline 5 & $\begin{array}{l}\text { Critérios de sucesso de impacto para o } \\
\text { negócio presente }\end{array}$ & $\begin{array}{l}\text { Botão de } \\
\text { opção }\end{array}$ & \\
\hline 6 & $\begin{array}{l}\text { Critérios de sucesso de impacto para o } \\
\text { negócio futuro }\end{array}$ & $\begin{array}{l}\text { Botão de } \\
\text { opção }\end{array}$ & \\
\hline 7 & $\begin{array}{c}\text { Critérios de sucesso de impacto para o } \\
\text { cliente }\end{array}$ & $\begin{array}{c}\text { Botão de } \\
\text { opção }\end{array}$ & \\
\hline 8 & Critérios de sucesso sustentabilidade & $\begin{array}{c}\text { Botão de } \\
\text { opção }\end{array}$ & \\
\hline 9 & Comentários livres & Campo aberto & Não há \\
\hline
\end{tabular}

0 teste de mediana de Mood é um teste não paramétrico que visa testar a igualdade de medianas de duas ou mais populações. Assim, diferentemente de testes como a análise de variância (ANOVA), tal teste não requer que as populações apresentem distribuição normal. Como as variáveis analisadas por meio desse teste (receita de projetos e nível de importância dos critérios de sucesso) não apresentam distribuição normal, optou-se por um teste não paramétrico. As análises foram elaboradas no software MINITAB e foram utilizadas para os seguintes propósitos: proposição de uma tipologia de projetos para a empresa estudada, sendo posteriormente validada pela análise da similaridade das características dos agrupamentos resultantes; e identificação de diferença significativa no nível de importância dos critérios de sucesso por tipo de projeto e tipo de stakeholder.

A análise fatorial foi utilizada para a validação das categorias de critérios de sucesso sugeridas a partir da revisão bibliográfica. Para a elaboração de tal análise, seguiram-se os estágios propostos por Hair et al. (2006). 0 problema analisado teve a perspectiva de uma análise exploratória, uma análise fatorial do tipo R, que busca avaliar o conjunto de variáveis (no caso, os critérios de sucesso), de forma a identificar dimensões implícitas, não facilmente observáveis.

\section{Resultados da análise documental dos projetos}

Esse tópico apresenta o diagnóstico da área de projetos da empresa no que concerne à caracterização de projetos da empresa em tipos.

Para a definição de uma tipologia aderente aos projetos desenvolvidos pela empresa foi feito um levantamento de dados de seus projetos, finalizados ou em andamento. Não havendo uma base de dados consolidada, foram consultados relatórios do ERP e planilhas de acompanhamento de projetos, a partir dos quais conseguiram-se informações completas de 54 projetos. Para cada projeto obtiveram-se informações referentes às categorias "tipo de produto", “área de negócio" e "escopo do projeto"; e às variáveis "receita", "margem percentual” e "prazo".

Quanto ao detalhamento das categorias, o "tipo de produto" refere-se à natureza do projeto desenvolvido, podendo ser descrito como "serviços profissionais" ou "soluções integradas". A "área de negócio" representa o mercado no qual o projeto está inserido, podendo compreender as áreas de óleo e gás (OG), química e petroquímica (QP), energia (EN) ou mineração e metalurgia (MM). Já o "escopo do projeto" compreende o tipo de trabalho desenvolvido no projeto, podendo ser classificado com E (Engineering - engenharia), EP (Engineeering and Procurement - engenharia 
e suprimento), EPC (Engineeering, Procurement and Construction - engenharia, suprimento e construção), EPCM (Engineeering, Procurement and Construction Management - gerenciamento da engenharia, suprimento e construção) ou EVTE (estudo de viabilidade técnica).

Quanto às variáveis, no caso da receita do projeto, também referenciada como porte do projeto, a empresa define intervalos de valores para classificar o projeto entre "mini”, "pequeno", "médio" e "grande". 0 mesmo foi feito para as variáveis "margem percentual" e "prazo". A definição desses intervalos levou em consideração a avaliação da própria empresa.

0 Tabela 3 apresenta um resumo das características e variáveis dos projetos e respectivas descrições. A análise dos 54 projetos por categorias e variáveis está no Apêndice A.

Os intervalos definidos para as variáveis estão apresentados na Tabela 4. Por questões de confidencialidade, para as variáveis "receita" e "margem" foi utilizado um parâmetro de referência, Rf e Mf respectivamente, para a apresentação dos intervalos. Especificamente para a margem, também utilizaram-se os parâmetros A e B, para preservar informações da empresa consideradas estratégicas.
Considerando as variáveis dos projetos apresentadas na Tabela 4, a receita (característica definidora do "porte" do projeto) é a mais importante na perspectiva da empresa, tanto do ponto de vista econômico quando gerencial. A receita do projeto, além de definir o impacto econômico do projeto para a empresa, influencia na definição dos profissionais que serão alocados ao projeto, de acordo com sua capacitação e experiência. Por exemplo, para projetos de grande porte ( $\mathrm{R}>=\mathrm{R} f+36.000)$, alocam-se profissionais mais seniores do que os demais. Dessa forma, com base nas principais categorias definidas pela empresa, apresentadas anteriormente, buscou-se analisar a distribuição da variável "receita" para diversos agrupamentos, de maneira a definir tipos de projetos que apresentassem certa homogeneidade.

Como primeiro passo, como forma de direcionamento da definição desses tipos, buscou-se analisar a receita dos projetos de acordo com suas diversas categorias, "tipo de produto”, “área de negócio" e "escopo do projeto", buscando verificar a existência de diferença significativa nesse fator para modalidades específicas de projetos. Conforme já comentado no tópico anterior, a variável receita não apresenta distribuição normal, portanto, utilizou-se o

Tabela 3. Características dos projetos da empresa estudada.

\begin{tabular}{|c|c|c|}
\hline Característica & Nome & Descrição \\
\hline \multirow[b]{3}{*}{ Categorias } & $\begin{array}{l}\text { Tipo de } \\
\text { produto }\end{array}$ & $\begin{array}{l}\text { - Soluções integradas } \\
\text { - Serviços profissionais }\end{array}$ \\
\hline & $\begin{array}{l}\text { Área de } \\
\text { negócio }\end{array}$ & $\begin{array}{l}\text { - Óleo e gás (OG) } \\
\text { - Química e Petroquímica (QP) } \\
\text { - Energia (EN) } \\
\text { - Mineração e Metalurgia (MM) }\end{array}$ \\
\hline & $\begin{array}{l}\text { Escopo do } \\
\text { projeto }\end{array}$ & $\begin{array}{l}\text { - E (Engineering): engenharia } \\
\text { - EP (Engineeering and Procurement): engenharia e } \\
\text { suprimento } \\
\text { - EPC (Engineeering, Procurement and Construction): } \\
\text { Engenharia, suprimento e construção } \\
\text { - EPCM (Engineeering, Procurement and Construction } \\
\text { Management): gerenciamento da engenharia, suprimento e } \\
\text { construção } \\
\text {-EVTE: estudo de viabilidade técnica }\end{array}$ \\
\hline \multirow{3}{*}{ Variáveis } & $\begin{array}{l}\text { Receita (ou } \\
\text { porte) }\end{array}$ & $\begin{array}{l}\text { Define o porte do projeto: mini, pequeno, médio e } \\
\text { grande }\end{array}$ \\
\hline & $\begin{array}{c}\text { Margem } \\
\text { percentual }\end{array}$ & Mini, pequena, média e grande \\
\hline & Prazo & Mini, pequeno, médio e grande \\
\hline
\end{tabular}


teste de mediana de Mood. Tais análises serviram de base para a proposição de uma tipologia de projetos para a empresa estudada.

Para uma análise inicial, levou-se em consideração a categoria "tipo de produto", por ser considerada como essencial para a caracterização dos projetos da empresa.

0 teste de Mood resultou num valor de $p$ ( $p$-value) bastante inferior a 5\% (inferior a 0,1\%), indicando a relevância dessa categoria de diferenciação dos projetos em relação ao seu porte. Assim, propôs-se a separação dos projetos por tipo de produto, o que resultou em 12 projetos classificados como "serviços profissionais" e 42, como "soluções integradas".

Posteriormente analisou-se a influência da "área de negócio" e do "escopo do projeto" no porte. Para tanto, dentro da cada categoria previamente definida, "serviços profissionais" e "soluções integradas", foram realizados testes de Mood para a receita dos projetos em função dessas categorias secundárias. Os resultados dos testes estão sumarizados na Tabela 5.

Para os projetos do tipo "soluções integradas" não foi possível elaborar o teste para a receita em relação ao escopo do projeto, pois o número de observações não era suficiente (havia apenas um projeto do tipo EP e 11 projetos do tipo EPC, num total de 12 projetos). Porém, dado que o valor da receita do projeto do tipo EP está compreendido no intervalo de valores de receita dos projetos do tipo
EPC, fundiram-se esses tipos de projeto. No caso do teste para a receita em relação à área de negócio, 0 valor de $\mathrm{p}$ obtido foi superior a 5\%. Esse resultado indica que não há diferença significativa para a receita dos projetos do tipo "soluções integradas" em relação à área de negócio. Como base nessas análises sugeriu-se que esses projetos componham um único agrupamento.

Quanto aos projetos do tipo "serviços profissionais", o teste para a receita em relação ao escopo do projeto resultou num valor de $\mathrm{p}$ inferior a 5\%, enquanto o teste para a receita em relação à área de negócio resultou num valor de $\mathrm{p}$ superior a 5\%. Esses resultados indicam que existe diferença significativa na receita desses projetos de acordo com seu escopo, mas não de acordo com a área de negócio. Essas análises sugerem uma subdivisão dos projetos do tipo "serviços profissionais" em novos agrupamentos, definidos de acordo com o escopo do projeto.

Consolidando as análises, procurou-se gerar categorias que resultassem em divisões significativas quanto ao porte dos projetos. 0 teste de Mood para a receita em relação à tipologia definida permitiu comprovar que as diferenças entre os tipos de projeto definidos são significativas, já que o valor de $p$ resultante foi de $0,0 \%$, inferior a $5 \%$.

0 agrupamento proposto tomou como base o escopo dos projetos, por resultar em maior homogeneidade das variáveis para cada categoria.

Tabela 4. Intervalos das variáveis dos projetos.

\section{Variável Receita ou porte (kR\$)}

Margem (\%)

Prazo (meses)

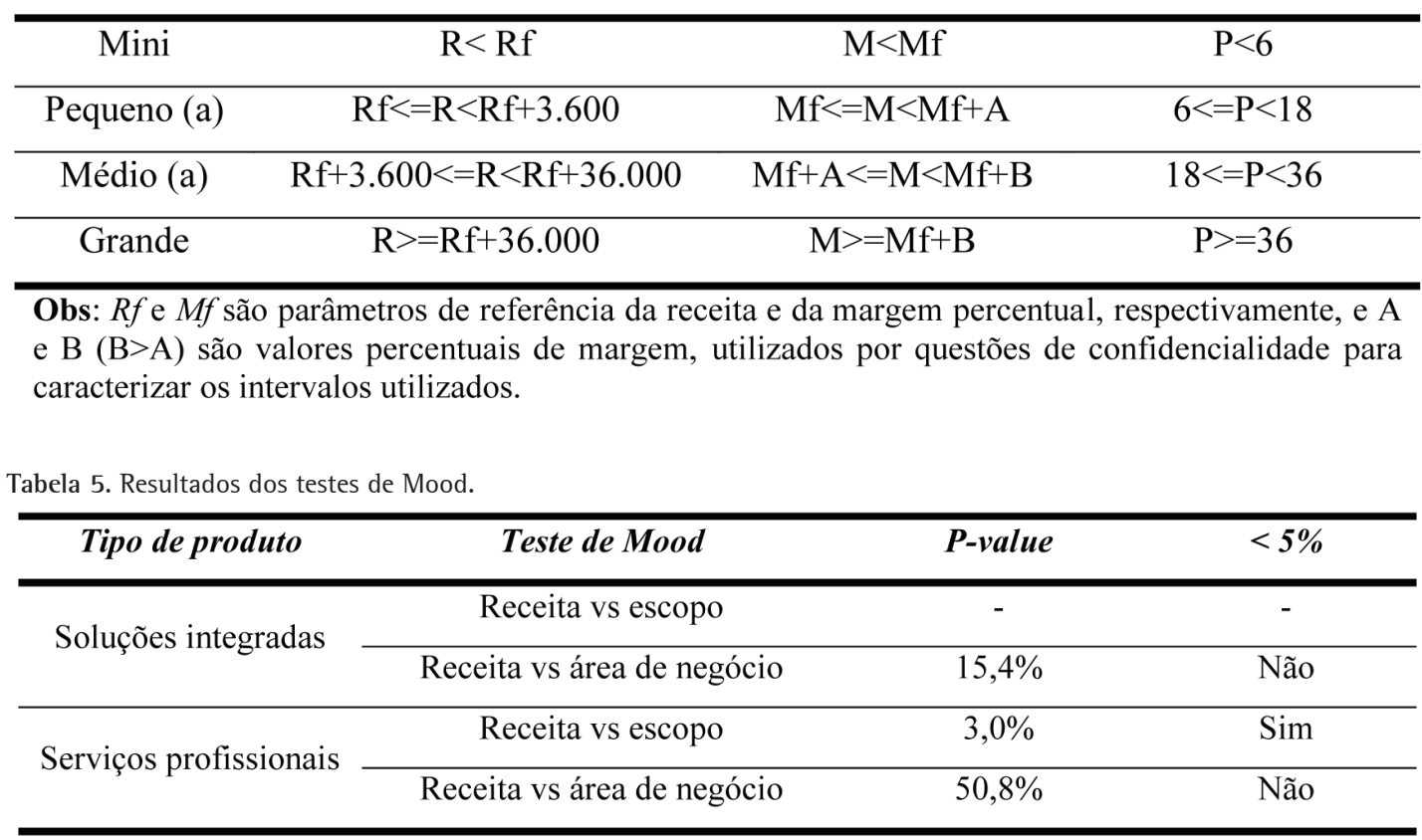


Inicialmente, propôs-se uma divisão entre serviços profissionais e soluções integradas, sendo aquela subdividida nos escopos E, EVTE e EPCM, e esta, nos escopos EP e EPC, conjuntamente. Após uma análise inicial das combinações geradas, visto que a divisão "serviços profissionais" de escopo E apresentava projetos com variedade significativa de porte, propôs-se uma nova quebra nessa divisão, diferenciando os projetos de maior e menor porte. Os agrupamentos resultantes e a quantidade de projeto em cada um deles estão apresentados na Tabela 6.

Os cinco tipos de projetos definidos a partir dessa análise podem ser caracterizados como segue:

0 tipo 1 compreende projetos cujo produto é caracterizado como "serviços profissionais", nos quais um serviço é prestado a um cliente. Seu escopo compreende somente o desenvolvimento do projeto de engenharia. Seu porte pode ser médio ou grande. A margem é normalmente média ou grande e o prazo é variado, porém com maior concentração em prazos pequenos, de 6 a 18 meses. Quanto às áreas de negócio presentes na categoria, incluem-se Energia, Química e Petroquímica e Mineração e Metalurgia, sendo a última com maior destaque.

0 tipo 2 difere do tipo 1, basicamente, em relação ao porte. Assim, também compreende projetos cujo produto é caracterizado como "serviços profissionais", cujo escopo consiste somente no desenvolvimento do projeto de engenharia. Seu porte pode ser mini ou pequeno. A margem pode variar, porém com maior destaque para margens grandes. 0 prazo também é variado, porém com maior concentração em prazos "mini" e "pequeno", menores que seis meses e de seis a 18 meses, respectivamente. Quanto às áreas de negócio presentes na categoria, incluem-se Energia, Química e Petroquímica, Óleo e Gás e Mineração e Metalurgia, sendo a última com maior destaque.
0 tipo 3 compreende projetos cujo produto é caracterizado como "serviços profissionais", nos quais um serviço é prestado a um cliente. Seu escopo compreende o estudo de viabilidade técnica de um projeto apresentado pelo cliente. Seu porte pode ser pequeno ou médio. A margem apresenta grande variabilidade, porém destaca-se a presença de projeto com margem mini. 0 prazo varia entre "mini" e "pequeno", menores que seis meses e de seis a 18 meses, respectivamente. Quanto às áreas de negócio presentes na categoria, incluem-se Química e Petroquímica e Mineração e Metalurgia, sendo a última com maior destaque.

0 tipo 4 compreende projetos cujo produto é caracterizado como "serviços profissionais", nos quais um serviço é prestado a um cliente. Seu escopo compreende o gerenciamento da engenharia, suprimento e construção de um empreendimento. Seu porte pode ser médio ou grande, sendo mais comum o primeiro. A margem varia ente pequena, média e grande, porém, destaca-se a presença de projeto com margem média. 0 prazo varia entre "pequeno" e "médio", de seis a 18 meses e de seis a 36 meses, respectivamente, com destaque para prazos "médios". Quanto às áreas de negócio presentes na categoria, incluem-se Energia, Óleo e Gás, Mineração e Petroquímica e Mineração e Metalurgia, sendo a última com maior destaque.

0 tipo 5 compreende projetos cujo produto é caracterizado como "soluções integradas", nos quais um projeto integrado é desenvolvido e entregue ao cliente. Seu escopo compreende duas modalidades de projeto: EPC e EP. Na modalidade EPC, o projeto engloba o projeto de engenharia, a compra dos materiais e a construção propriamente dita. $\mathrm{Na}$ modalidade EP estão incluídos somente a engenharia e o suprimento. Seu porte é grande e sua margem varia, porém, com destaque para projetos com margem

Tabela 6. Características da tipologia definida.

\begin{tabular}{|c|c|c|c|c|}
\hline Tipologia & Tipo de produto & $\begin{array}{c}\text { Escopo do } \\
\text { projeto }\end{array}$ & Porte & $\begin{array}{l}\text { Quantidade de } \\
\text { projetos } \\
\text { classificados }\end{array}$ \\
\hline Tipo 1 & \multirow{4}{*}{$\begin{array}{c}\text { Serviços } \\
\text { profissionais }\end{array}$} & $\bar{E}$ & Grande e médio & 12 \\
\hline Tipo 2 & & $\mathrm{E}$ & Pequeno e mini & 19 \\
\hline Tipo 3 & & EVTE & Médio e pequeno & 5 \\
\hline Tipo 4 & & EPCM & Grande e médio & 6 \\
\hline Tipo 5 & $\begin{array}{l}\text { Soluções } \\
\text { integradas }\end{array}$ & EP e EPC & Grande & 12 \\
\hline
\end{tabular}


média. 0 prazo varia entre "pequeno", "médio" e "grande", com destaque para prazos "médios", de 18 a 36 meses. Quanto às áreas de negócio presentes na categoria, incluem-se Energia, Química e Petroquímica, Mineração e Metalurgia e Óleo e Gás, sendo a última com maior destaque.

\section{Resultados do levantamento junto aos stakeholders}

Nessa seção apresentam-se os resultados do levantamento do tipo survey realizado na empresa estudada. A estatística descritiva dos resultados do levantamento são apresentadas no Apêndice B.

Considerando os projetos analisados na seção anterior foi feita uma seleção prévia dos projetos, cujos stakeholders seriam considerados na pesquisa tipo survey. Os critérios considerados para essa seleção dos projetos foram: presença na empresa dos profissionais que exerceram a função de diretor ou gerente de projeto e planejamento financeiro no projeto analisado, existência de processo de acompanhamento de indicadores de desempenho do projeto, diversidade de respondentes e balanceamento do número de projetos analisados por tipo. Com base nos critérios mencionados, selecionaram-se 34 projetos.

Para cada projeto foram selecionados três respondentes: o gerente, o diretor do projeto e o profissional responsável pelo planejamento financeiro. Essa amostra foi validada pelo responsável pelo PMO. Esses respondentes foram analisados segundo a classificação proposta pelo PMl (Project Management Institute, 2008), com base em seus níveis de poder e interesse no sucesso dos projetos. 0 gerente, o diretor do projeto e o profissional de planejamento financeiro possuem alto nível de interesse no sucesso do projeto no qual trabalham. Além de garantir a remuneração desses profissionais, o sucesso dos projetos gera avaliações positivas por parte da alta gestão, abrindo portas para novas oportunidades de trabalho. Por outro lado, o nível de poder de influência diverge para esses profissionais. Enquanto o poder do gerente ou diretor de projeto é alto, devido ao seu poder formal na hierarquia do projeto, o poder do profissional de planejamento financeiro é baixo, já que não detém autoridade formal para influenciar outras áreas do projeto. A classificação desses profissionais que participaram do levantamento está ilustrada na Figura 2.

Vale destacar, no entanto, que outros stakeholders importantes, externos aos projetos, não foram pesquisados, dadas as restrições impostas pela empresa estudada quanto ao acesso a clientes e outros envolvidos.

\subsection{Análise dos critérios de sucesso}

Dentre os critérios de sucesso que aparecem com maior importância destacaram-se: cumprimento de cronograma (prazo), cumprimento de requisitos, qualidade do serviço, cumprimento de prazo e clareza na comunicação (ver Apêndice B). Já os critérios de menor destaque foram: parcela de mercado, tecnologia nova, nova competência essencial, capacidade dos fornecedores e nova capacidade organizacional.

É interessante observar que a maioria dos critérios de maior destaque pertence à categoria "eficiência", enquanto os de menor destaque pertencem, principalmente, à categoria "impacto para o negócio futuro". Esse resultando evidencia uma preocupação com resultados de mais curto prazo, em detrimento de resultados verificados somente no longo prazo.

A Figura 3 apresenta a síntese da estatística descritiva dos dados, destacando os critérios de maior importância e os critérios de menor importância.

\subsection{Análise fatorial dos dados}

Hair et al. (2006) sugerem que a amostra deve possuir mais observações que variáveis, sendo 50 o número mínimo de observações a serem analisadas. Como na presente pesquisa constam 59 observações e 29 variáveis, a amostra está de acordo com tais regras. Para se averiguar a multicolinearidade, os autores sugerem o teste de esfericidade de Bartlett e o valor da medida da adequação da amostra (Measure of Sampling Adequacy - MSA). 0 teste de esfericidade mostrou que as correlações, quando tomadas coletivamente, são significativas a um nível inferior a $0,1 \%$, enquanto o valor da medida de adequação da amostra com um todo foi de 0,567.

Hair et al. (2006) apresentam dois métodos para a extração de fatores: análise dos componentes e análise dos fatores comuns. Segundo Velicer \&

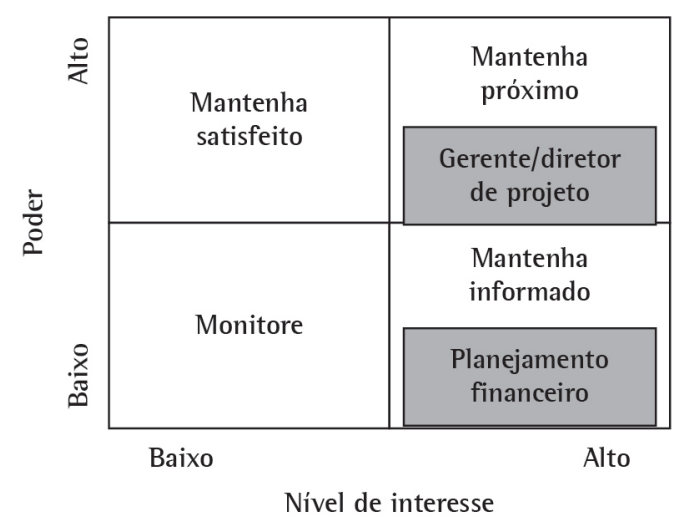

Figura 2. Classificação dos respondentes. 


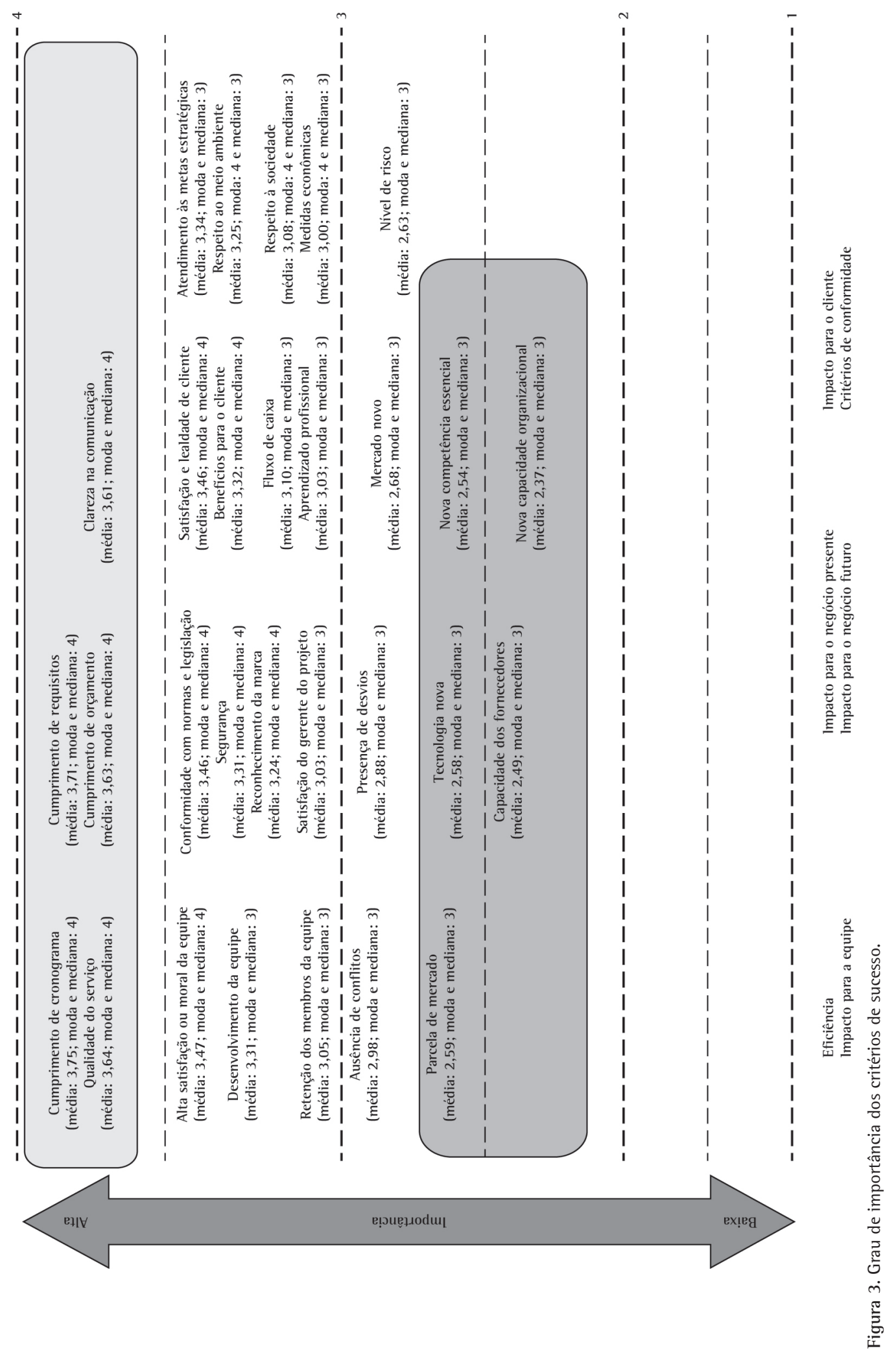


Jackson (1990), pesquisas empíricas demonstram resultados similares para os dois métodos. Dessa forma, optou-se pela análise dos componentes. Buscando-se obter uma distribuição de carga em que cada variável tivesse uma carga significativa em apenas um fator, foram feitas diversas rotações, ortogonais e oblíquas, até que se chegou a um conjunto de cinco fatores relacionados a 23 variáveis.

Uma vez obtida uma solução adequada, buscou-se atrelar um significado aos fatores identificados. A denominação proposta baseou-se no quadro teórico. A matriz de fatores resultante e a denominação dos fatores identificados estão apresentadas na Tabela 7.

0 Tabela 8 apresenta a comparação das categorias definidas a partir da análise fatorial e da síntese da literatura. Os critérios de sucesso destacados em cinza representam aqueles que foram eliminados na análise fatorial, por não ter sido identificada correlação significativa entre eles e as categorias de fatores geradas. Os critérios destacados em preto representam aqueles que na categorização definida a partir da pesquisa de campo foram relacionados a uma categoria diferente da proposta a partir da pesquisa bibliográfica.

De maneira geral, as categorias apresentaram certa semelhança, porém em alguns casos foi sugerida outra denominação, considerando os novos critérios atrelados à categoria ou até mesmo a junção de categorias. A categoria "eficiência”, sugerida com base em levantamento bibliográfico, também pode ser identificada a partir da análise da pesquisa de campo, porém com algumas alterações. Os critérios "cumprimento de cronograma" e "clareza na comunicação" não foram identificados como

Tabela 7. Matriz de solução de fatores resultante.

\begin{tabular}{|c|c|c|c|c|c|c|}
\hline & & \multicolumn{5}{|c|}{ Fatores } \\
\hline & & 1 & 2 & 3 & 4 & 5 \\
\hline \multirow{5}{*}{ 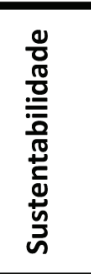 } & Atendimento às metas estratégicas &, 538 & ,385 & 093 & ,288 &,- 018 \\
\hline & Respeito ao meio ambiente & ,828 & 156 & ,068 & 243 & ,004 \\
\hline & Respeito à sociedade & ,845 & ,270 & 027 & 247 & ,091 \\
\hline & Conformidade com normas e legislação & ,815 & 295 & 042 & 095 & 075 \\
\hline & Segurança &, 745 & 103 &,- 021 &,- 120 & ,469 \\
\hline \multirow{5}{*}{ 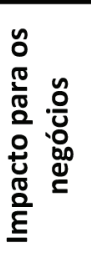 } & Medidas econômicas &,- 120 & ,682 &, 001 & 289 & 309 \\
\hline & Tecnologia nova & ,392 & ,719 & 007 & 222 &,- 043 \\
\hline & Mercado novo & 328 & 691 &,- 105 &,- 098 &,- 042 \\
\hline & Nova competência essencial & 230 & ,903 &,- 007 &,- 044 &,- 051 \\
\hline & Nova capacidade organizacional & ,296 & ,807 & ,116 & 127 &,- 079 \\
\hline \multirow{5}{*}{ 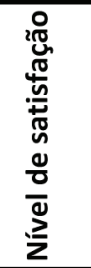 } & Alta satisfação ou moral da equipe &,- 125 & 226 & 690 &,- 040 & 330 \\
\hline & Retenção dos membros da equipe &,- 153 &,- 020 & ,563 & 299 & 106 \\
\hline & Ausência de conflitos & 137 &,- 198 & ,656 & 242 &,- 334 \\
\hline & Satisfação do gerente do projeto & , 118 & 008 & ,754 &,- 098 &,- 160 \\
\hline & Benefícios para o cliente & 153 &,- 022 &, 787 & 092 & 142 \\
\hline \multirow{4}{*}{ 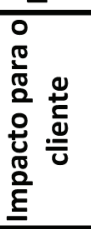 } & Fluxo de caixa & ,245 & 116 &,- 097 &, 726 & 027 \\
\hline & Cumprimento de requisitos & 172 &,- 019 & 157 & ,711 & ,202 \\
\hline & Satisfação e lealdade do cliente & 124 & 194 & ,350 & ,516 & 197 \\
\hline & Reconhecimento da marca & ,119 & 168 & 089 & ,777 &,- 142 \\
\hline \multirow{4}{*}{ 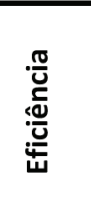 } & Cumprimento do orçamento (custo) & 023 &,- 027 &,- 003 & 409 & ,584 \\
\hline & Capacidade dos fornecedores & 252 & 200 &, 085 &,- 048 & ,607 \\
\hline & Presença de desvios &, 013 &,- 236 &,- 091 & 164 & ,733 \\
\hline & Nível de risco & 182 & ,035 & ,454 &,- 150 & ,657 \\
\hline
\end{tabular}


Tabela 8. Critérios de sucesso: pesquisa de campo versus quadro teórico.

\begin{tabular}{|c|c|c|c|}
\hline \multicolumn{2}{|r|}{ Pesquisa bibliográfica } & \multicolumn{2}{|r|}{ Pesquisa de campo } \\
\hline \multicolumn{3}{|c|}{ Critérios de sucesso } & Critérios de sucesso \\
\hline \multirow{5}{*}{ 音 } & $\begin{array}{l}\text { Cumprimento de cronograma } \\
\text { (prazo) }\end{array}$ & \multirow{5}{*}{$\frac{\sqrt[\pi]{e}}{\frac{\pi}{0}}$} & \\
\hline & Cumprimento do orçamento (custo) & & Cumprimento do orçamento (custo) \\
\hline & Capacidade dos fornecedores & & Capacidade dos fornecedores \\
\hline & Clareza na comunicação & & Nível de risco \\
\hline & Presença de desvios & & Presença de desvios \\
\hline \multirow{5}{*}{ 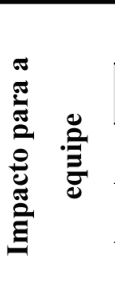 } & Alta satisfação ou moral da equipe & \multirow{5}{*}{ 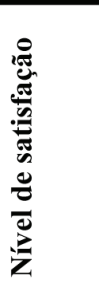 } & Alta satisfação ou moral da equipe \\
\hline & Desenvolvimento da equipe & & Benefícios para o cliente \\
\hline & Retenção dos membros da equipe & & Retenção dos membros da equipe \\
\hline & Ausência de conflitos & & Ausência de conflitos \\
\hline & Satisfação do gerente do projeto & & Satisfação do gerente do projeto \\
\hline \multirow{7}{*}{ 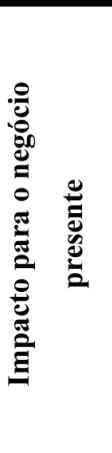 } & Medidas econômicas & \multirow{11}{*}{ 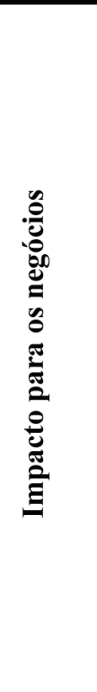 } & Medidas econômicas \\
\hline & Parcela de mercado & & \\
\hline & Fluxo de caixa & & \\
\hline & Qualidade do serviço & & \\
\hline & Nível de risco & & \\
\hline & Aprendizado profissional & & \\
\hline & Atendimento às metas estratégicas & & \\
\hline \multirow{4}{*}{ 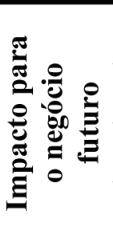 } & Tecnologia nova & & Tecnologia nova \\
\hline & Mercado novo & & Mercado novo \\
\hline & Nova competência essencial & & Nova competência essencial \\
\hline & Nova capacidade organizacional & & Nova capacidade organizacional \\
\hline \multirow{4}{*}{ 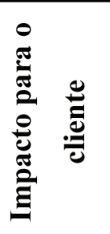 } & Cumprimento de requisitos & \multirow{4}{*}{ 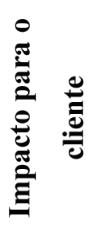 } & Cumprimento de requisitos \\
\hline & Benefícios para o cliente & & Fluxo de caixa \\
\hline & Satisfação e lealdade do cliente & & Satisfação e lealdade do cliente \\
\hline & Reconhecimento da marca & & Reconhecimento da marca \\
\hline \multirow{5}{*}{ 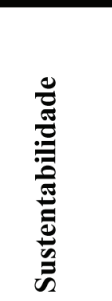 } & Respeito ao meio ambiente & \multirow{5}{*}{ 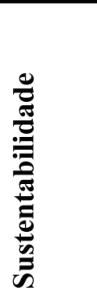 } & Respeito ao meio ambiente \\
\hline & Respeito à sociedade & & Respeito à sociedade \\
\hline & Conformidade com normas e & & Conformidade com normas e legislação \\
\hline & legislação & & \\
\hline & Segurança & & Segurança \\
\hline
\end{tabular}


correlacionados a essa categoria, enquanto que 0 critério "nível de risco" foi incorporado a ela.

No caso da categoria inicialmente denominada “impacto para a equipe”, a partir da pesquisa bibliográfica, com a inclusão do critério "benefícios para o cliente" sugeriu-se uma nova denominação: "nível de satisfação". Tal categoria, além de englobar critérios de medida de satisfação dos integrantes da equipe do projeto e do próprio gerente, também considera o nível de satisfação do cliente.

A categoria "impacto para o negócio futuro" permaneceu bastaste semelhante, havendo apenas a inclusão do critério "medidas econômicas", antes relacionado a categoria "impacto para o negócio presente”. Visto que essa distinção entre impactos para o negócio presente e futuro não se mostrou significativa a partir dos resultados da pesquisa de campo, sugeriu-se a fusão dessas duas categorias em uma só, denominada "impacto para os negócios".

Com relação à categoria "impacto para o cliente" houve uma substituição do critério "benefícios para o cliente" pelo critério "fluxo de caixa". Apesar de esse critério estar relacionado à organização desenvolvedora do projeto, pode-se considerar que ele tem grande influência sobre o cliente, já que a saúde financeira da empresa é de extremo interesse para seu contratante, pois pode comprometer fortemente os resultados que o cliente visa obter.

No caso da categoria "sustentabilidade" houve a inclusão de um critério de sucesso relacionado a questões internas na organização: "atendimento às metas estratégicas". Finalmente, uma análise mais cuidadosa deve ser feita em relação aos critérios eliminados durante a análise fatorial. Os critérios "cumprimento de cronograma", "qualidade do serviço" e "clareza na comunicação" destacaram-se como critérios de maior importância, porém não foram categorizados em nenhuma das cinco categorias definidas a partir da análise fatorial (ver Figura 3). Dado o elevado nível de importância de tais critérios, segundo a perspectiva dos profissionais consultados, sugere-se um acompanhamento à parte, com maior destaque desses critérios. Os demais critérios eliminados também obtiverem importância baixa.

\subsection{Análise da influência do tipo de stakeholders}

Para analisar a influência das perspectivas de diferentes stakeholders quanto ao nivel de importância dos critérios de sucesso analisados, utilizou-se novamente o teste de mediana de Mood. Esse teste foi elaborado no software MINITAB e os resultados estão na Tabela 9.
Observa-se que não foram identificadas diferenças significativas na importância, para a maioria dos critérios de sucesso, entre gerentes ou diretores de projeto e os profissionais de planejamento financeiro, exceto para dois desses critérios (ver Tabela 9).

0 primeiro critério que apresentou diferença significativa foi “ausência de conflitos". Esse critério é visto como mais importante do ponto de vista dos profissionais do planejamento financeiro que da perspectiva dos diretores ou gerentes de projetos. Essa diferença pode ser explicada pelo nível de envolvimento desses profissionais no dia a dia do projeto. Os profissionais de planejamento financeiro são responsáveis pela consolidação de informações de diversas áreas do projeto e, por isso, interagem com profissionais de diferentes disciplinas. Assim, estão mais susceptíveis a conflitos no desenvolvimento de suas atividades de cunho mais operacional. Além disso, respondem diretamente ao diretor ou gerente de projeto que, por sua vez, pode criar tensões ao fazer uso de seu poder formal na maneira como supervisiona seus subordinados.

0 critério "medidas econômica" também apresentou diferença significativa, dado que os diretores ou gerentes de projeto destacaram a sua importância. Esse resultado pode ser explicado pelo fato de esses profissionais serem cobrados justamente pelo valor da receita e margem dos seus projetos. Portanto, esses aspectos são foco de grande atenção desses profissionais. Por outro lado, é curioso observar que os profissionais da área denominada "planejamento financeiro" não deem tanto destaque às medidas econômicas. Esse resultado pode ser decorrente do fato de que tais profissionais, apesar de gerenciarem as finanças do projeto, têm pouca influência sobre seu desempenho econômico, já que as decisões sobre o projeto são tomadas pelo seu gerente ou diretor.

Com base nesses resultados e análises, pode-se concluir que, para a maioria dos critérios de sucesso avaliados, o nível de importância não difere significativamente, de acordo com a perspectiva dos stakeholders analisados na empresa estudada.

\subsection{Análise da influência da tipologia}

Analogamente, para a análise da influência das tipologias de projeto no nível de importância dos critérios de sucesso analisados, utilizou-se novamente o teste de mediana de Mood. Nesse caso foram analisados os níveis de importância definidos para cada critério, de acordo com os diversos tipos de projeto (ver Tabela 10).

É interessante observar que alguns critérios de sucesso apresentaram diferença significativa 
Tabela 9. Teste de Mood para análise da influência do tipo de stakeholders.

\begin{tabular}{|c|c|c|c|c|}
\hline \multirow[b]{2}{*}{ Critérios de sucesso } & \multirow[b]{2}{*}{ P-value } & \multirow[b]{2}{*}{$<5 \%$} & \multicolumn{2}{|c|}{ Destaques } \\
\hline & & & $\begin{array}{c}\text { Menor } \\
\text { importância }\end{array}$ & $\begin{array}{c}\text { Maior } \\
\text { importância }\end{array}$ \\
\hline Cumprimento do orçamento (custo) & $72,0 \%$ & Não & - & - \\
\hline Capacidade dos fornecedores & $62,1 \%$ & Não & - & - \\
\hline Presença de desvios & $69,7 \%$ & Não & - & - \\
\hline Alta satisfação ou moral da equipe & $7,0 \%$ & Não & - & - \\
\hline Retenção dos membros da equipe & $72,0 \%$ & Não & - & - \\
\hline Ausência de conflitos & $0,5 \%$ & Sim & G/DP & PF \\
\hline Satisfação do gerente do projeto & $89,6 \%$ & Não & - & - \\
\hline Medidas econômicas & $2,2 \%$ & Sim & $\mathrm{PF}$ & G/DP \\
\hline Fluxo de caixa & $20,6 \%$ & Não & - & - \\
\hline Nível de risco & $62,1 \%$ & Não & - & - \\
\hline Atendimento às metas estratégicas & $45,3 \%$ & Não & - & - \\
\hline Tecnologia nova & $68,7 \%$ & Não & - & - \\
\hline Mercado novo & $24,8 \%$ & Não & - & - \\
\hline Nova competência essencial & $47,1 \%$ & Não & - & - \\
\hline Nova capacidade organizacional & $99,3 \%$ & Não & - & - \\
\hline Cumprimento de requisitos & $10,4 \%$ & Não & - & - \\
\hline Benefícios para o cliente & $29,3 \%$ & Não & - & - \\
\hline Satisfação e lealdade do cliente & $75,2 \%$ & Não & - & - \\
\hline Reconhecimento da marca & $22,8 \%$ & Não & - & - \\
\hline Respeito ao meio ambiente & $94,3 \%$ & Não & - & - \\
\hline Respeito à sociedade & $99,3 \%$ & Não & - & - \\
\hline Conformidade com normas e legislação & $32,6 \%$ & Não & - & - \\
\hline Segurança & $79,2 \%$ & Não & - & - \\
\hline
\end{tabular}

segundo o tipo de projeto. Para projetos do tipo 1, cujo escopo é basicamente o desenvolvimento do projeto de engenharia, o critério "nova competência essencial" apresentou importância menor que nos demais projetos, possivelmente devido à simplicidade desse tipo de projeto, se comparado com os demais desenvolvidos na empresa, e à sua abrangência, pois compreende diversas áreas de negócio e não se concentra num mercado específico. É interessante observar também que, para projetos do tipo 3 , o nível de importância do critério "cumprimento de orçamento" apresentou importância inferior em relação aos demais projetos. Esse resultado pode ser explicado pela natureza do projeto, cujo escopo compreende um estudo de viabilidade, já que a apropriação de receita ocorre, muitas vezes, na forma de ordens de serviço emitidas pela contratada com base nas horas trabalhadas.

A Figura 4 apresenta um resumo dos critérios que apresentaram significativa diferença de importância entre os tipos de projeto.

Pode-se observar que a tipologia 5 apresentou maior destaque para uma quantidade maior de critérios de sucesso. Essa tipologia apresenta particularidades 
Tabela 10. Teste de Mood para análise da influência da tipologia de projeto.

\begin{tabular}{|c|c|c|c|c|}
\hline \multirow[b]{2}{*}{ Critérios de sucesso } & \multirow[b]{2}{*}{ P-value } & \multirow[b]{2}{*}{$<5 \%$} & \multicolumn{2}{|c|}{ Destaques } \\
\hline & & & $\begin{array}{c}\text { Menor } \\
\text { importância }\end{array}$ & $\begin{array}{c}\text { Maior } \\
\text { importância }\end{array}$ \\
\hline Cumprimento do orçamento (custo) & $1,2 \%$ & Sim & Tipo 3 & - \\
\hline Capacidade dos fornecedores & $1,4 \%$ & Sim & - & Tipos 4 e 5 \\
\hline Presença de desvios & $3,0 \%$ & Sim & - & Tipos 1 e 5 \\
\hline Alta satisfação ou moral da equipe & $60,2 \%$ & Não & - & - \\
\hline Retenção dos membros da equipe & $7,7 \%$ & Não & - & - \\
\hline Ausência de conflitos & $26,7 \%$ & Não & - & - \\
\hline Satisfação do gerente do projeto & $28,4 \%$ & Não & - & - \\
\hline Medidas econômicas & $4,1 \%$ & Sim & - & Tipo 5 \\
\hline Fluxo de caixa & $42,2 \%$ & Não & - & - \\
\hline Nível de risco & $0,4 \%$ & Sim & - & Tipos 4 e 5 \\
\hline Atendimento às metas estratégicas & $1,1 \%$ & Sim & - & Tipos 3 e 5 \\
\hline Tecnologia nova & $10,1 \%$ & Não & - & - \\
\hline Mercado novo & $1,2 \%$ & Sim & - & Tipo 3 \\
\hline Nova competência essencial & $3,6 \%$ & Sim & Tipo 1 & - \\
\hline Nova capacidade organizacional & $20,7 \%$ & Não & - & - \\
\hline Cumprimento de requisitos & $86,0 \%$ & Não & - & - \\
\hline Benefícios para o cliente & $92,6 \%$ & Não & - & - \\
\hline Satisfação e lealdade do cliente & $56,8 \%$ & Não & - & - \\
\hline Reconhecimento da marca & $7,1 \%$ & Não & - & - \\
\hline Respeito ao meio ambiente & $8,8 \%$ & Não & - & - \\
\hline Respeito à sociedade & $20,0 \%$ & Não & - & - \\
\hline Conformidade com normas e legislação & $73,6 \%$ & Não & - & - \\
\hline Segurança & $3,2 \%$ & Sim & - & Tipos 4 e 5 \\
\hline
\end{tabular}

bastante distintas das demais, já que abrange um tipo particular de produto, denominado "soluções integradas", no qual a empresa participa de todas as fases do projeto, incluindo etapas de engenharia, construção, montagem e diligenciamento. Esses projetos são de porte maior, sendo responsáveis pela maior parte da receita obtida pela empresa. Em relação aos critérios destacados como de maior importância, podem-se fazer as seguintes observações: capacidade dos fornecedores, medidas econômicas, nível de risco, atendimento às metas estratégicas e segurança

Semelhantemente, os projetos do tipo 4 apresentaram destaque para os seguintes critérios: “capacidade dos fornecedores", "nível de risco" e "segurança”. Nesses projetos, a contratada é responsável pelo gerenciamento da engenharia, fornecimento e construção do empreendimento. Apesar de o escopo desse tipo de projeto ser menor que o do tipo 5, a empresa ainda compartilha os riscos durante a fase da construção. Ademais, a adequada gestão dos fornecedores é fundamental nesse tipo de projeto, não só para garantir sua qualidade, mas também o adequando cumprimento do seu cronograma.

Projetos do tipo 3 apresentaram destaque para os seguintes critérios: "atendimento às metas estratégicas" e "mercado novo". Esse tipo de projeto tem uma 


\begin{tabular}{|c|c|}
\hline $\begin{array}{c}\text { Presença de desvios } \\
\text { Tipo } 1 \\
\begin{array}{c}\text { Nova competêncial } \\
\text { essencia }\end{array}\end{array}$ & $\begin{array}{l}\text { Atendimento às metas estratégicas } \\
\text { Mercado novo }\end{array}$ \\
\hline $\begin{array}{l}\text { Capacidade dos fornecedores } \\
\text { Nivel de risco } \\
\text { Segurança }\end{array}$ & $\begin{array}{l}\text { Capacidade dos fornecedores } \\
\text { Medidas econômicas } \\
\text { Nivel de risco } \\
\text { Atendimento às metas estratégicas } \\
\text { Segurança }\end{array}$ \\
\hline
\end{tabular}

Figura 4. Critérios com diferença significativa entre tipos.

importância estratégica peculiar, já que apresenta margens relativamente baixas e consequentemente pouco contribuem para o faturamento da empresa. Porém, o desenvolvimento desse tipo de projeto visa alcançar um objetivo posterior: desenvolver um projeto de maior porte resultante do estudo elaborado. Nesse sentido, esse tipo de projeto também permite que a empresa explore novos mercados, nos quais não apresenta competência reconhecida.

Com relação a projetos do tipo 1 , o critério destacado foi "presença de desvios". Esses projetos são basicamente de engenharia. No caso de contratos do tipo preço global, nos quais um preço fixo é predeterminado no contrato, o acompanhamento dos desvios das horas de trabalho previstas é crucial para garantir a sua rentabilidade.

Finalmente é importante observar que o tipo 2 de projeto não demonstrou destaque em nenhum dos critérios que apresentaram diferença significativa de importância. Essa constatação sugere que tal categoria poderia ser mesclada com outra. Dado que esse tipo havia sido destacado em relação ao tipo 1 meramente por nível de receita e já que o escopo de ambos os projetos se restringe ao desenvolvimento da engenharia, sugere-se que essas duas categorias passem a representar uma só. Dessa forma, ao invés dos cinco tipos de projeto sugeridos, trabalhar-se-á com uma tipologia composta por quatro tipos de projetos. Para se evitar confusão entre as categorias anteriormente definidas, serão utilizadas letras, ao invés de números, para categorizar essas quatro categorias.

\section{Conclusões e recomendações}

0 presente trabalho visou investigar a influência das variáveis tipologia de projeto e tipo de stakeholder nos critérios de sucesso em projetos. Os resultados da pesquisa permitiram a constatação de que a tipologia dos projetos influencia no nível de importância atribuído aos critérios de sucesso, conforme sugerido pela literatura (Clark \& Fujimoto, 1991; Vidal \& Marle, 2008; Cleland \& King, 1967; Maximiano, 1997; Westerveld, 2003; Shenhar et al., 2005; Shenhar \& Dvir, 2007; Carvalho \& Rabechini Junior, 2011). Porém o mesmo não ocorre para os diferentes stakeholders analisados, conforme esperado (Kerzner, 2010; Project Management Institute, 2008). Houve grande alinhamento entre os stakeholders entrevistados em todos os projetos, o que se deve em parte à forte cultura de gestão de projetos desenvolvida na organização estudada, cujo PMO data de mais de uma década. Por outro lado a ausência de stakeholders externos na amostra prejudicou uma análise mais ampla da interferência dos stakeholders.

Outra contribuição relevante do trabalho foi a análise dos critérios de sucesso a partir da análise da literatura em seis categorias e respectivas variáveis (ver Tabela 1) e sua posterior confrontação com os dados de campo, que chegaram a categorias bastante alinhadas às teóricas, agrupando impacto para o negócio presente e futuro em um único fator extraído da análise fatorial exploratória (ver Tabela 8).

É importante ressaltar que como implicações para a prática, as etapas descritas e seguidas no presente trabalho podem ser facilmente replicadas em qualquer 
organização, em busca dos critérios de sucesso customizados aos tipos de projetos organizacionais. Os métodos utilizados, uma vez compreendidos, são de fácil aplicação e as ferramentas utilizadas, tais como MINITAB e SPSS, apresentam versões gratuitas disponíveis. 0 fato de o método ser replicável não implica que os resultados sejam generalizáveis, pelo contrário, é nesse aspecto que está parte da riqueza da análise, dado que as contingências da organização e de seus projetos são espelhadas nos critérios de sucesso assumidos.

Como sugestões para trabalhos futuros colocam-se um aprofundamento da análise de stakeholders e das razões que levaram a diferenças não significativas, conforme sugerido pela literatura. Uma análise que se faz necessária em uma agenda futura é a inclusão de stakeholders externos à organização na análise.

\section{Referências}

Atkinson, R. (1999). Project management: cost, time and quality, two best guesses and a phenomenon, its time to accept other success criteria. International Journal of Project Management, 17(6), 337-342. http://dx.doi. org/10.1016/S0263-7863(98)00069-6

Balachandra, R., \& Friar, J. H. (1997). Factors for success in R\&D projects and new product innovation: a contextual framework. IEEE Transactions on Engineering Management, 44(3), 276-287. http://dx.doi. $\operatorname{org} / 10.1109 / 17.618169$

Barclay, C. (2008). Towards an intergrated measurement of is project performance: the project performance scorecard. Information Systems Fronties, 10(3), 331-345. http:// dx.doi.org/10.1007/s10796-008-9083-6

Belassi, W., \& Tukel, 0. (1996). A new framework for determining critical success/failure factors in projects. International Journal of Project Management, 14(3), 141151. http://dx.doi.org/10.1016/0263-7863(95)00064-X

Carvalho, M. M., \& Rabechini Junior, R. (2011). Fundamentos em Gestão de Projetos: Construindo competências para gerenciar projetos: teoria e casos (3. ed.). São Paulo: Atlas.

Chan, A., \& Chan, A. (2004). Key performance indicators for measuring construction success. Benchmarking: An International Journal, 11(2), 203-221. http://dx.doi. org/10.1108/14635770410532624

Clark, K., \& Fujimoto, T. (1991). Product development performance. Boston: Harvard Business School Press.

Cleland, D., \& King, W. (1967). Systems analysis and project management. New York: McGraw-Hill.

Constructon Industry Institute - Cll. (2006). Leading indicators during project execution (Resarch Summary 220-1). University of Texas in Austin.

Cooke-Davies, T. (2002). The" real" success factors on projects. International Journal of Project Management, 20(3), 185-190. http://dx.doi.org/10.1016/S02637863(01)00067-9

Cummings, J., \& Doh, J. (2000). ldentifying who matters: mapping key players in multiple environments. California
Management Review, 42(2), 83-104. http://dx.doi. org/10.2307/41166034

De Wit, A. (1988). Measurement of project success. International Journal of Project Management, 6(3), 164170. http://dx.doi.org/10.1016/0263-7863(88)90043-9

Elattar, S. (2009). Towards developing an improved methodology for evaluating performance and achieving success in construction projects. Scientific Research and Essays, 4(6), 549-554.

Evaristo, R., \& Van Fenema, P. C. (1999). A typology of project management: Emergence and evolution of new forms. International Journal of Project Management, 17(5), 275-281. http://dx.doi.org/10.1016/S02637863(98)00041-6

Fortune, J., \& White, D. (2006). Framing of project critical success factors by a systems model. International Journal of Project Management, 24(1), 53-65. http://dx.doi. org/10.1016/j.jproman.2005.07.004

Freeman, R. (1984). Strategic management: A stakeholder approach. Boston: Pitman.

Hair, J., Black, W. C., Babin, B. J., \& Anderson, R. E. (2006). Multivariate Data Analysis. Upper Saddle River: Pearson Prentice Hall.

Hatush, Z., \& Skitmore, M. (1997). Evaluating contractor prequalification data: selection criteria and project success factors. Construction Management and Economics, 15(2), 129-147. http://dx.doi. org/10.1080/01446199700000002

Kerzner, H. (2010). The future of project management. In: The future of project management. São Paulo: International Institute for Learning.

Kometa, S., Olomolaiye, P., \& Harris, F. (1995). An evaluation of clients' needs and responsibilities in the construction process. Engineering, construction and Architectural management, 2(1), 57-76. http://dx.doi.org/10.1108/ eb021003

Kumaraswamy, M., \& Thorpe, A. (1996). Systematizing construction project evaluations. Journal of Management in Engineering, 12(1), 34-39. http://dx.doi.org/10.1061/ (ASCE)0742-597X(1996)12:1(34)

Lim, C., \& Mohamed, M. (1999). Criteria of project success: an exploratory re-examination. International Journal of Project Management, 17(4), 243-248. http://dx.doi. org/10.1016/S0263-7863(98)00040-4

Maximiano, A. (1997). Administração de projetos: como transformar idéias em resultados. São Paulo: Atlas.

Mitchell, R., Agle, B., \& Wood, D. (1997). Toward a theory of stakeholder identification and salience: defining the principle of who and what really counts. Academy of Management Review, 22(4), 853-886.

Navarre, C., \& Schaan, J. (1990). Design of project management systems from top management's perspective. Project Management Journal, 21(2), 19-27.

Office of Government Commerce - OGC. (2002). Managing successful programmes. Norwich: The Stationery Office.

Office of Government Commerce - OGC. (2005). Managing successful project with PRINCE2. Norwich: The Stationery Office.

Pinto, J., \& Slevin, D. (1988). Project success: definitions and measurement techniques. Project Management Journal, 19(1), 67-72. 
Pocock, J. B., Hyun, C. T., Liu, L. Y., \& Kim, M. K. (1996). Relationship between project interaction and performance indicators. Journal of Construction Engineering and Management, 122(2), 165-176. http:// dx.doi.org/10.1061/(ASCE)0733-9364(1996)122:2(165)

Project Management Institute - PMI. (2008). Um guia do conhecimento em gerenciamento de projetos (guia PMBOK). Newton Square: Project Management Institute.

Rabechini Junior, R, \& Carvalho, M. M. (2009). Gestão projetos inovadores em uma perspectiva contingencial: análise teórico-conceitual e proposição de um modelo. Revista de Administração e Inovação, 6(3), 63.

Sanvido, V., Grobler, F., Parfitt, K., Guvenis, M., \& Coyle, M. (1992). Critical success factors for construction projects. Journal of Construction Engineering and Management, 118(1), 94-111. http://dx.doi.org/10.1061/(ASCE)07339364(1992)118:1(94)

Shenhar, A. J. (2001). One size does not fit all projects: Exploring classical contingency domains. Management Science, 47(3), 394-414. http://dx.doi.org/10.1287/ mnsc.47.3.394.9772

Shenhar, A. J., Tishler, A., Dvir, D., Lipovetsky, S., \& Lechler, T. (2002). Refining the search for project success factors: A multivariate, typological approach. $R$ and $D$ Management, 32(2), 111-126. http://dx.doi.org/10.1111/14679310.00244

Shenhar, A. J., Dvir, D., Milosevic, D., Mulenburg, J., Patanakul, P., Reilly, R., Ryan, M., Sage, A., Sauser, B., Srivannaboon, S., Stefanovic, J., \& Thamhain, H. T (2005). Toward a NASA-specific project management framework. Engineering Management Journal, 17(4), 8-16.
Shenhar, A., \& Dvir, D. (2007). Reinventing project management: The diamond approach to successful growth and innovation. Boston: Harvard Business School Press.

Siegelaub, J. M. (2010). Da tripla à sêxtupla restrição: um modelo de destaque para controle de projetos no PRINCE2. Mundo Project Management, 6(33).

Toor, S., \& Ogunlana, S. (2009). Beyond the the 'iron triangle': Stakeholder perception of key performance indicators (KPIs) for large-scale public sector development projects. International Journal of Project Management, 28(3), 228236. http://dx.doi.org/10.1016/j.ijproman.2009.05.005

Velicer, W., \& Jackson, D. (1990). Component analysis versus common factor analysis: Some issues in selecting an appropriate procedure. Multivariate Behavioral Research, 25(1), 1-28. http://dx.doi.org/10.1207/ s15327906mbr2501_1

Vidal, L. A., \& Marle, F. (2008). Understanding project complexity: Implications on project management. Kybernetes, 37(8), 1094-1110. http://dx.doi. org/10.1108/03684920810884928

Westerveld, E. (2003). The Project Excellence Model ${ }^{\circledR}$ : linking success criteria and critical success factors. International Journal of Project Management, 21(6), 411-418. http:// dx.doi.org/10.1016/S0263-7863(02)00112-6

\section{Agradecimentos}

Agradecemos aos avaliadores do trabalho, que muito contribuíram para a melhoria do artigo com os seus comentários e sugestões. Agradecemos também à CAPES e ao CNPq, pelo suporte ao projeto de pesquisa.

\section{Project success criteria: an exploratory study on the influence of the variables project typology and type of stakeholder}

\section{Abstract}

In this study, we aim to understand the influence of the variables project typology and type of stakeholder on project success criteria. We used a quantitative and qualitative methodological approach which encompasses a review of the literature followed by a field research analysis using hybrid research strategy. The research occurred in a company whose business includes integrated solutions in engineering and infrastructure in various industrial sectors. Data were collected from projects at 54 organizations and from a survey with 59 project managers and other professionals involved in project management activities. The results showed a significant influence of the type of project in the success criteria level of importance, but the same did not occur regarding the type of stakeholder.

\section{Keywords}

Project management. Success criteria. Typology. Stakeholder. Contingent theory. 
Apêndice A. Caracterização dos projetos analisados.

\begin{tabular}{|c|c|c|c|c|c|}
\hline Tipologia & Projeto & Porte & Margem percentual & Prazo & Área de negócio \\
\hline \multirow{12}{*}{ Tipo 1} & $\mathrm{P} 1$ & Grande & Grande & Médio & MM \\
\hline & P2 & Médio & Grande & Pequeno & MM \\
\hline & P3 & Grande & Média & Médio & MM \\
\hline & P4 & Médio & Grande & Pequeno & MM \\
\hline & P5 & Médio & Grande & Mini & MM \\
\hline & P6 & Médio & Grande & Pequeno & MM \\
\hline & P7 & Médio & Grande & Pequeno & MM \\
\hline & P8 & Médio & Média & Pequeno & EG \\
\hline & P9 & Médio & Grande & Grande & QP \\
\hline & P10 & Médio & Média & Pequeno & EG \\
\hline & $\mathrm{P} 11$ & Médio & Grande & Pequeno & MM \\
\hline & $\mathrm{P} 12$ & Grande & Grande & Médio & MM \\
\hline \multirow{19}{*}{ Tipo 2} & P13 & Pequeno & Grande & Grande & MM \\
\hline & P14 & Pequeno & Mini & Mini & QP \\
\hline & P15 & Pequeno & Pequena & Mini & OG \\
\hline & P16 & Pequeno & Grande & Mini & OG \\
\hline & P17 & Pequeno & Média & Médio & MM \\
\hline & P18 & Mini & Grande & Pequeno & EG \\
\hline & P19 & Pequeno & Grande & Pequeno & MM \\
\hline & P20 & Pequeno & Pequena & Mini & QP \\
\hline & P21 & Pequeno & Pequena & Mini & MM \\
\hline & P22 & Pequeno & Pequena & Pequeno & MM \\
\hline & P23 & Pequeno & Média & Pequeno & MM \\
\hline & P24 & Pequeno & Mini & Mini & MM \\
\hline & P25 & Mini & Grande & Mini & MM \\
\hline & P26 & Pequeno & Grande & Pequeno & EG \\
\hline & P27 & Pequeno & Grande & Pequeno & MM \\
\hline & P28 & Pequeno & Grande & Pequeno & QP \\
\hline & P29 & Pequeno & Grande & Pequeno & EG \\
\hline & Р30 & Pequeno & Média & Pequeno & MM \\
\hline & P31 & Pequeno & Grande & Pequeno & MM \\
\hline \multirow{5}{*}{ Tipo 3} & P32 & Pequeno & Grande & Mini & MM \\
\hline & P33 & Médio & Mini & Pequeno & QP \\
\hline & P34 & Médio & Mini & Pequeno & QP \\
\hline & P35 & Pequeno & Pequena & Mini & MM \\
\hline & P36 & Pequeno & Média & Mini & MM \\
\hline \multirow{6}{*}{ Tipo 4} & P37 & Médio & Pequena & Médio & OG \\
\hline & P38 & Médio & Grande & Médio & EG \\
\hline & P39 & Grande & Média & Médio & QP \\
\hline & P40 & Médio & Grande & Pequeno & QP \\
\hline & P41 & Médio & Média & Médio & QP \\
\hline & P42 & Médio & Média & Médio & $\mathrm{QP}$ \\
\hline \multirow{12}{*}{ Tipo 5} & P43 & Grande & Grande & Médio & MM \\
\hline & P44 & Grande & Média & Médio & QP \\
\hline & P45 & Grande & Pequena & Médio & MM \\
\hline & P46 & Grande & Média & Médio & $\mathrm{QP}$ \\
\hline & P47 & Grande & Média & Médio & OG \\
\hline & P48 & Grande & Média & Grande & OG \\
\hline & P49 & Grande & Média & Médio & OG \\
\hline & P50 & Grande & Pequena & Grande & OG \\
\hline & P51 & Grande & Mini & Pequeno & $\mathrm{QP}$ \\
\hline & P52 & Grande & Média & Médio & OG \\
\hline & P53 & Grande & Pequena & Grande & QP \\
\hline & P54 & Grande & Média & Médio & EG \\
\hline
\end{tabular}


Apêndice B. Estatística descritiva dos resultados do levantamento.

\begin{tabular}{|c|c|c|c|c|c|c|c|}
\hline Categoria & Critério & Média & Mediana & Moda & Desvio & Mínimo & Máximo \\
\hline Eficiência & $\begin{array}{l}\text { Cumprimento de cronograma } \\
\text { (prazo) }\end{array}$ & 3,75 & 4 & 4 & 0,47 & 2 & 4 \\
\hline Impacto para o cliente & Cumprimento de requisitos & 3,71 & 4 & 4 & 0,45 & 3 & 4 \\
\hline $\begin{array}{c}\text { Impacto para o negócio } \\
\text { presente }\end{array}$ & Qualidade do serviço & 3,64 & 4 & 4 & 0,60 & 1 & 4 \\
\hline Eficiência & $\begin{array}{l}\text { Cumprimento do orçamento } \\
\text { (custo) }\end{array}$ & 3,63 & 4 & 4 & 0,61 & 2 & 4 \\
\hline Eficiência & Clareza na comunicação & 3,61 & 4 & 4 & 0,55 & 2 & 4 \\
\hline Impacto para a equipe & Alta satisfação ou moral da equipe & 3,47 & 4 & 4 & 0,81 & 0 & 4 \\
\hline Impacto para o cliente & Satisfação e lealdade do cliente & 3,46 & 4 & 4 & 0,74 & 1 & 4 \\
\hline Sustentabilidade & $\begin{array}{l}\text { Conformidade com normas e } \\
\text { legislação }\end{array}$ & 3,46 & 4 & 4 & 0,87 & 0 & 4 \\
\hline $\begin{array}{c}\text { Impacto para o negócio } \\
\text { presente }\end{array}$ & $\begin{array}{c}\text { Atendimento às metas } \\
\text { estratégicas }\end{array}$ & 3,34 & 3 & 3 & 0,65 & 1 & 4 \\
\hline Impacto para o cliente & Benefícios para o cliente & 3,32 & 4 & 4 & 1,02 & 0 & 4 \\
\hline Impacto para a equipe & Desenvolvimento da equipe & 3,31 & 3 & 3 & 0,74 & 0 & 4 \\
\hline Sustentabilidade & Segurança & 3,31 & 4 & 4 & 1,25 & 0 & 4 \\
\hline Sustentabilidade & Respeito ao meio ambiente & 3,25 & 3 & 4 & 0,98 & 0 & 4 \\
\hline Impacto para o cliente & Reconhecimento da marca & 3,24 & 4 & 4 & 0,87 & 1 & 4 \\
\hline $\begin{array}{c}\text { Impacto para o negócio } \\
\text { presente }\end{array}$ & Fluxo de caixa & 3,10 & 3 & 3 & 0,84 & 1 & 4 \\
\hline Sustentabilidade & Respeito à sociedade & 3,08 & 3 & 4 & 1,11 & 0 & 4 \\
\hline Impacto para a equipe & Retenção dos membros da equipe & 3,05 & 3 & 3 & 0,81 & 0 & 4 \\
\hline Impacto para a equipe & Satisfação do gerente do projeto & 3,03 & 3 & 3 & 0,76 & 1 & 4 \\
\hline $\begin{array}{c}\text { Impacto para o negócio } \\
\text { presente }\end{array}$ & Aprendizado profissional & 3,03 & 3 & 3 & 0,76 & 1 & 4 \\
\hline $\begin{array}{c}\text { Impacto para o negócio } \\
\text { presente }\end{array}$ & Medidas econômicas & 3,00 & 3 & 4 & 1,07 & 0 & 4 \\
\hline Impacto para a equipe & Ausência de conflitos & 2,98 & 3 & 3 & 0,79 & 1 & 4 \\
\hline Eficiência & Presença de desvios & 2,88 & 3 & 3 & 1,01 & 0 & 4 \\
\hline $\begin{array}{c}\text { Impacto para o negócio } \\
\text { futuro }\end{array}$ & Mercado novo & 2,68 & 3 & 3 & 1,19 & 0 & 4 \\
\hline $\begin{array}{c}\text { Impacto para o negócio } \\
\text { presente }\end{array}$ & Nível de risco & 2,63 & 3 & 3 & 1,29 & 0 & 4 \\
\hline $\begin{array}{c}\text { Impacto para o negócio } \\
\text { presente }\end{array}$ & Parcela de mercado & 2,59 & 3 & 3 & 0,99 & 0 & 4 \\
\hline $\begin{array}{c}\text { Impacto para o negócio } \\
\text { futuro }\end{array}$ & Tecnologia nova & 2,58 & 3 & 3 & 1,15 & 0 & 4 \\
\hline $\begin{array}{c}\text { Impacto para o negócio } \\
\text { futuro }\end{array}$ & Nova competência essencial & 2,54 & 3 & 3 & 1,33 & 0 & 4 \\
\hline Eficiência & Capacidade dos fornecedores & 2,49 & 3 & 4 & 1,58 & 0 & 4 \\
\hline $\begin{array}{c}\text { Impacto para o negócio } \\
\text { futuro }\end{array}$ & Nova capacidade organizacional & 2,37 & 3 & 3 & 1,23 & 0 & 4 \\
\hline
\end{tabular}

Cada tom de cinza ilustra uma categoria de critério de sucesso, conforme Quadro 1. 